Article

\title{
A Novel Polymer Electrolyte Matrix Incorporating Ionic Liquid into Waterborne Polyurethane for Lithium-Ion Battery
}

\author{
Xiaoli Liu ${ }^{\mathbb{D}}$, Yu Zhan, Chenying Zhao, Yuefeng Su, Zhen Ge * and Yunjun Luo *(D) \\ School of Materials Science and Engineering, Beijing Institute of Technology, Beijing 100081, China; \\ 2120171181@bit.edu.cn (X.L.); 1120171444@bit.edu.cn (Y.Z.); 3220180999@bit.edu.cn (C.Z.); \\ suyuefeng@bit.edu.cn (Y.S.) \\ * Correspondence: gzandlsy@bit.edu.cn (Z.G.); yjluo@bit.edu.cn (Y.L.); Tel./Fax: +86-010-68911608 (Z.G. \& Y.L.)
}

Received: 27 May 2020; Accepted: 3 July 2020; Published: 8 July 2020

\begin{abstract}
Ionic liquid has relatively high conductivity at room temperature and good electrochemical stability. Ionic liquid polymer electrolytes have some advantages of both ionic liquid and polymer. In this work, 1-alkyl-3-(2', $3^{\prime}$-dihydroxypropyl)imidazolium chloride (IL-Cl) was incorporated into waterborne polyurethane chain to composite all-solid-state polymer electrolyte matrices. The structure, thermal stability, mechanical property and ionic conductivity of the matrices were investigated by Fourier transform infrared spectroscopy (FTIR), thermogravimetric Analysis (TGA), tensile measurement and electrochemical impedance spectroscopy (EIS). The results demonstrated that when the content of IL-Cl was $14 \mathrm{wt} \%$, the mechanical property of film was optimized, with a maximum tensile strength of $36 \mathrm{MPa}$ and elongation at break of $1030 \%$. In addition, as for the film with IL-Cl content of $16 \mathrm{wt} \%$, its oxygen index value increased to $25.2 \%$ and ionic conductivity reached a maximum of $1.2 \times 10^{-5} \mathrm{~S} \cdot \mathrm{cm}^{-1}$ at room temperature, showing high flame retardancy and ionic conductivity.
\end{abstract}

Keywords: ionic liquid; waterborne polyurethane; all-solid-state polymer electrolyte matrices

\section{Introduction}

Lithium ( $\mathrm{Li}$ ) metal is considered as the most desired anode for next-generation rechargeable batteries because of its high theoretical specific capacity of $3860 \mathrm{mAh} \cdot \mathrm{g}^{-1}$ and lowest electrode potential ( $-3.040 \mathrm{~V}$ vs. standard hydrogen electrode) [1]. Li-ion batteries have been widely used in portable and consumable electronic devices, hybrid and all-electric vehicles nowadays [2]. However, as traditional electrolyte, liquid electrolyte will give rise to some serious problems when the operating temperature rises, such as leakage and gas explosions [3,4]. Thus, its practical applications were limited. Clearly, it is extremely urgent to seek some electrolytes with superior safety for the rapid development of Li-ion and/or Li batteries in the next-generation large-scale applications [5,6]. All-solid-state Li-ion batteries are considered to be most promising to address the safety challenges of the current Li-ion batteries, which possess great advantages over the liquid or gel electrolytes, including better safety, non-flammability, non-leakage and excellent design flexibility $[7,8]$. Due to heightening environment concerns during the past few decades, waterborne polyurethane (WPU) has attracted more attention with its excellent properties, such as adhesion, flexibility, gloss and weatherability. Meanwhile, WPU contains two-phase structure which is soft segments and hard segments. The whole system benefits from these two-phases since that the hard parts afford spacial stability and the soft phases are conducive to good ionic conductivity [9]. Due to this unique structure, WPU has been identified as a potential candidate polymer matrix for solid polymer electrolytes (SPEs) recently [10]. Bao et al. 
prepared comb-like nonionic WPU based SPEs with ionic conductivity reaching $5.44 \times 10^{-6} \mathrm{~S} \cdot \mathrm{cm}^{-1}$ when the electrolyte contained $15 \mathrm{wt} \% \mathrm{LiClO}_{4}$ at $40{ }^{\circ} \mathrm{C}$ and SPE15 possessed a wide electrochemical stability window of 0-5 V (vs. $\mathrm{Li}+/ \mathrm{Li}$ ) and thermal stability at $140^{\circ} \mathrm{C}$ [11]. Ren et al. reported a WPU as SPE, exhibiting an ionic conductivity of $5.14 \times 10^{-5} \mathrm{~S} \cdot \mathrm{cm}^{-1}$ at $25^{\circ} \mathrm{C}$ with the addition of LiTFSI and all-solid-state $\mathrm{LiFePO}_{4} / \mathrm{SPE} / \mathrm{Li}$ battery based on WPU12-20\%Li delivered discharge specific capacities of 159 and $162 \mathrm{mAh} \cdot \mathrm{g}^{-1}$ under 60 and $80{ }^{\circ} \mathrm{C}$ at $0.1 \mathrm{C}$, respectively [12]. Liu et al. developed a series of comb-like cationic polyurethanes based SPEs, showing an ionic conductivity of $1.1 \times 10^{-4} \mathrm{~S} \cdot \mathrm{cm}^{-1}$ when the electrolyte contains $50 \mathrm{wt} \% \mathrm{LiClO}_{4}$ at room temperature [13]. Although the WPU based SPEs possess good thermal stability and mechanical properties, the ionic conductivity is still too low, especially at room temperature.

Ionic liquid can realize environment protection and cycle economics due to its advantages including non-flammable and non-toxic property, low vapor pressure, high conductivity, high ion transference number, wide electrochemical window and good stability performance [14-16]. Therefore, ionic liquid is able to be an important component in SPE [17,18]. However, so far as we know, the chemical combination of ionic liquid and WPU has little been reported yet. Based on these considerations, herein, the WPU-ionic liquid membranes were investigated for the first time as polymer electrolytes matrices for all-solid-state Li-ion batteries. The polymer electrolytes with different IL-Cl content were prepared through incorporating IL-Cl as a chain-extender into WPU matrix by a self-emulsion method. Owing to high hydrophilicity of IL-Cl, WPU was successfully prepared without emulsifier. In this way, the problem of unstable process and poor repeatability of product caused by traditional emulsifier addition can be avoided. FTIR, particle size distribution analysis, zeta potential analysis, tensile measurement, limiting oxygen index (LOI) and EIS were used to investigate the structure and properties of prepared polymer electrolyte matrices.

\section{Experimental}

\subsection{Materials and Reagents}

Polytetramethylene glycol (PTMG, Mn = 2000, industrial grade, $98 \mathrm{wt} \%$ purity) and isophorone diisocyanate (IPDI, industrial grade, $98 \mathrm{wt} \%$ purity) were purchased from Bayer Corp (Leverkusen, German). Dibutyltin dilaurate (DBTDL, AR, $99 \mathrm{wt} \%$ purity) and acetone (AR, $99.5 \mathrm{wt} \%$ purity)were supplied by China National Pharmaceutical Group Co., Ltd (Beijing, China). IL-Cl was synthesized by ultrasound method.

\subsection{Preparation of WPU Films}

The preparation of WPU films can be described as Scheme 1. Firstly, quantitative PTMG was put into a $500 \mathrm{~mL}$ three-neck flask equipped with a mechanical stirrer. PTMG was dried under vacuum at $110^{\circ} \mathrm{C}$ for $40 \mathrm{~min}$. Then the condensing tube was installed and the system was cooled down to $60{ }^{\circ} \mathrm{C}$. Quantitative IPDI and $0.1 \mathrm{~mL}$ DBTDL were added into the flask and the pre-polymerization proceeded at $80{ }^{\circ} \mathrm{C}$ for $2 \mathrm{~h}$. The NCO-terminated prepolymer was obtained. Then quantitative IL-Cl was added to extend the backbones, some acetone was also added to reduce the viscosity. The mixture continued to react at $95{ }^{\circ} \mathrm{C}$ for another $4 \mathrm{~h}$. After that, the prepolymer was poured into some distilled water and dispersed by stirring at $3000 \mathrm{rpm}$ for $15 \mathrm{~min}$, finally yielding IWPU emulsion. The solid content of IWPU emulsion was $20 \mathrm{wt} \%$, and the molar ratio of $-\mathrm{NCO} /-\mathrm{OH}$ of the reactants was 1.2. The amounts of raw materials corresponding for different IL-Cl content were listed in Table 1.

Then IWPU emulsion was poured into some PTFE moulds and placed at room temperature for $7 \mathrm{~d}$ to remove the most of solvent. At last, the dense films were dried under vacuum at $70{ }^{\circ} \mathrm{C} \mathrm{for} 12 \mathrm{~h}$ to remove the residual solvent. 


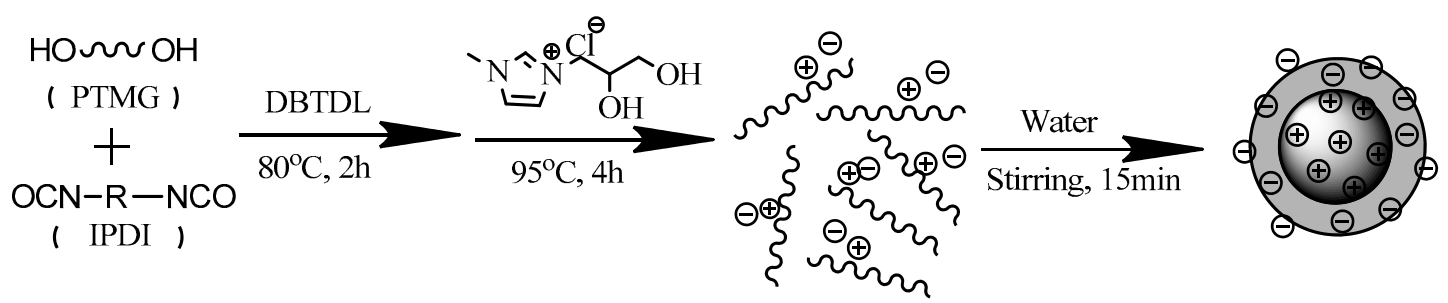

Scheme 1. Preparation of IWPU.

Table 1. The formula of IWPU prepared with different content of IL-Cl.

\begin{tabular}{|c|c|c|c|c|}
\hline Sample Name & m (PTMG)/g & $\mathrm{m}(\mathrm{IPDI}) / \mathrm{g}$ & m (IL-Cl)/g & $\mathrm{m}\left(\mathrm{H}_{2} \mathrm{O}\right) / \mathrm{g}$ \\
\hline IWPU-13 & 20.00 & 8.57 & 4.27 & 131.36 \\
\hline IWPU-14 & 20.00 & 9.25 & 4.76 & 136.04 \\
\hline IWPU-15 & 20.00 & 9.98 & 5.20 & 140.72 \\
\hline IWPU-16 & 20.00 & 10.77 & 5.86 & 146.52 \\
\hline IWPU-17 & 20.00 & 11.62 & 6.48 & 152.40 \\
\hline
\end{tabular}

\subsection{Characterization}

(1) FTIR

FTIR spectra of the prepared films were tested using a Nicolet 8700 Fourier transform infrared spectrometer (Thermo Fisher Scientific, Waltham, MA, USA). The spectra were collected between $4000 \mathrm{~cm}^{-1}$ and $650 \mathrm{~cm}^{-1}$ with a resolution of $4 \mathrm{~cm}^{-1}$. Each sample was scanned for 32 times and the air was taken as a background peak.

(2) Particle Size and Zeta Potential Test

One or two drops of emulsions were added into distilled water and diluted to one-thousandth mass fraction. The particle size and zeta potential of IWPU were determined at $25^{\circ} \mathrm{C}$ in $120 \mathrm{~s}$ using a Zetasizer Nano ZS90 laser particle sizer (Malvern Company, Malvern, UK).

(3) Gel permeation chromatography (GPC)

The molecular weights and polydispersity indices of IWPU films were determined by PL-GPC 220 (Agilent Technologies, Santa Clara, CA, USA). IWPU films were diluted with DMF and then injected into the GPC column at a flow rate of $1.0 \mathrm{~mL} / \mathrm{min}$ at $60^{\circ} \mathrm{C}$. Nearly monodisperse polystyrene was used for molecular weight calibration. The sample concentration was $2 \mathrm{mg} / \mathrm{mL}$.

(4) TGA

TGA was performed by a TGA/DSC1 thermogravimetric analyzer (METTLER TOLEDO, Zurich, Switzerland). The samples were scanned at a scanning rate of $10{ }^{\circ} \mathrm{C} / \mathrm{min}$ from $30^{\circ} \mathrm{C}$ to $600{ }^{\circ} \mathrm{C}$ under $\mathrm{N}_{2}$ atmosphere. The specimen of $5 \mathrm{mg}$ was taken in alumina crucible and placed in TG apparatus.

(5) DSC

DSC of IWPU films were performed by METTLER DSC1 (METTLER TOLEDO, Zurich, Switzerland) at a scanning rate of $10^{\circ} \mathrm{C} / \mathrm{min}$ from -100 to $150{ }^{\circ} \mathrm{C}$ under $\mathrm{N}_{2}$ atmosphere.

(6) Tensile Measurement

The thickness of films were maintained at $3 \mathrm{~mm} \pm 0.3 \mathrm{~mm}$ and then the films were made into dumbbell-shapes. The maximum tensile strength and elongation at break of samples were measured by an AGS-J electronic universal testing machine (Excellence in Science, Kyoto, Japan) as per ASTM D-412. The test was proceeded at a speed of $100 \mathrm{~mm} / \mathrm{min}$ at $25^{\circ} \mathrm{C}$ with load capacity of $20 \mathrm{~N}$ and accuracy of $\pm 1 \%$. All measurements were the mean values of three runs.

(7) LOI

LOI was measured according to ASTM D-2863. The apparatus used was an HC-2 oxygen index meter (Jionglei Equipment Company, Nanjing, China). The specimens used for the test had dimensions of $127 \times 10 \times 3 \mathrm{~mm}^{3}$.

(8) EIS 
Ionic conductivity measurements with alternation current were conducted on a CHI660E electrochemical workstation (Chenhua Equipment company, Shanghai, China) in a frequency range from $100 \mathrm{kHz}$ to $1 \mathrm{~Hz}$ under an oscillation potential of $5 \mathrm{mV}$. The electrolyte film was sandwiched between stainless steel blocking electrodes ( $15 \mathrm{~cm}$ in diameter). The impedance response was gauged at room temperature. Complex impedance plots were computed from the raw experimental data. The conductivity values were calculated from the bulk resistance according to the equation.

$$
\sigma=\frac{L}{R \times S}
$$

where $R(\Omega)$ is the resistance of the bulk electrolyte, $L(\mathrm{~cm})$ is the thickness of the film and $S\left(\mathrm{~cm}^{2}\right)$ is the area of electrode.

\section{Results and Discussion}

\subsection{FTIR}

The FTIR spectra of IWPU films were roughly similar where one of them was presented in Figure 1. Whereas, its absorption peaks were listed in Table 2 . The absorption peaks at $3300 \mathrm{~cm}^{-1}(\mathrm{~N}-\mathrm{H}$ stretching vibration) and $1727 \mathrm{~cm}^{-1}$ ( $\mathrm{C}=\mathrm{O}$ stretching vibration) were corresponded to the formation of urethane (NH-COO-) by reaction of -NCO group and -OH group. The appearance of absorption peaks at $1540 \mathrm{~cm}^{-1}\left(-\mathrm{C}=\mathrm{C},-\mathrm{C}=\mathrm{N}\right.$ deformation vibration), $1365 \mathrm{~cm}^{-1}$ (Imidazole skeletal stretching) and $1250 \mathrm{~cm}^{-1}$ (Imidazole symmetric stretching) demonstrated that IL-Cl had reacted and formed polyurethane chain. The absorption peaks at $1109 \mathrm{~cm}^{-1}, 1027 \mathrm{~cm}^{-1}$ (C-O-C asymmetric stretching vibration) and $801 \mathrm{~cm}^{-1}$ (-C-O-C- symmetric stretching) in Figure 1 were assigned to PTMG segments. In summary, these results indicated that WPU with IL-Cl had been prepared successfully.

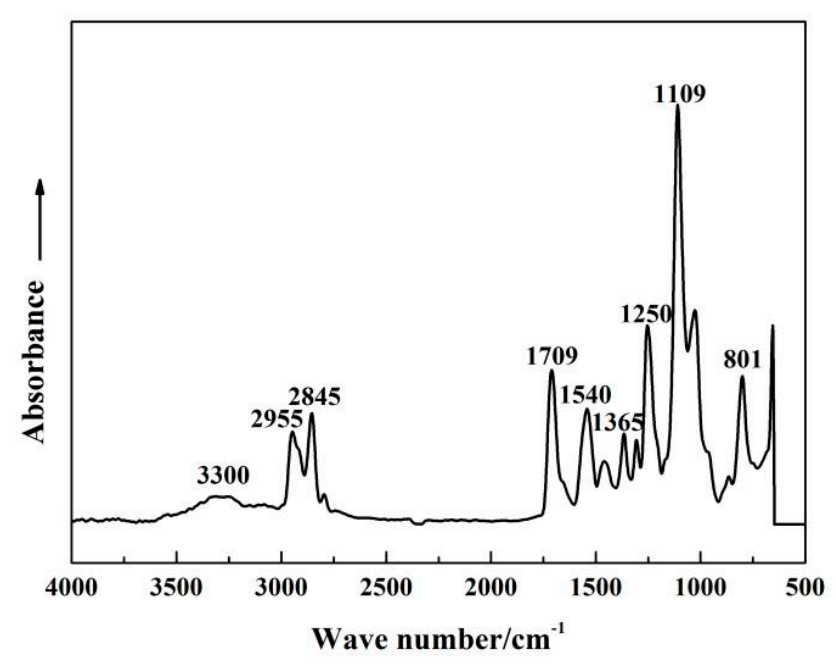

Figure 1. FTIR spectrum of IWPU.

Table 2. FTIR peak positions of IWPU.

\begin{tabular}{cc}
\hline Wave Number/cm & Assignments \\
\hline 3300 & $\mathrm{~N}-\mathrm{H}$ stretching \\
2945,2855 & $-\mathrm{CH}_{3},-\mathrm{CH}_{2}$ - stretching \\
1709 & $-\mathrm{C}=\mathrm{O}$ stretching \\
1540 & $-\mathrm{C}=\mathrm{C},-\mathrm{C}=\mathrm{N}$ deformation \\
1365 & Imidazole skeletal stretching \\
1250 & Imidazole symmetric stretching \\
1109,1027 & $-\mathrm{C}-\mathrm{O}-\mathrm{C}-$ asymmetric stretching \\
801 & $-\mathrm{C}-\mathrm{O}-\mathrm{C}-$ symmetric stretching \\
\hline
\end{tabular}




\subsection{Particle Size and Zeta Potential}

The emulsion appearance, particle size and zeta potential of IWPUs were shown in Table 3. The particle size tended to increase first and then remain unchangeable with the increase of IL-Cl content. There was a critical value when IL-Cl content was $15 \%$. This can be explained as follows: during the reverse phase of emulsification process, the steric hindrance effect of imidazole ring contained in IL-Cl prevented the hydrophobic segments of polyurethane from being entangled and retracted with each other. Therefore, the density of the particles decreased and the particle size became larger. Emulsion particles collided with each other during the storage process and partly became larger, realizing an increase of PDI (Polydispersity Index). When the content of IL-Cl exceeded 15\%, the particle size didn't change significantly. Besides, the appearance of IWPU emulsions was milky white and uniform, which was consistent with the results of zeta potential. The values of zeta potential were generally between 40 and $50 \mathrm{mV}$, indicating good stability of the emulsions [19].

Table 3. Appearance and stability of IWPUs.

\begin{tabular}{clcc}
\hline Sample Name & Appearance & Particle Size/nm (PDI) & Zeta Potential/mV \\
\hline IWPU-13 & Milky white, uniform & $106.8(0.134)$ & 43.5 \\
IWPU-14 & Milky white, uniform & $123.4(0.087)$ & 43.8 \\
IWPU-15 & Milky white, uniform & $185.7(0.143)$ & 43.0 \\
IWPU-16 & Milky white, uniform & $179.3(0.143)$ & 41.8 \\
IWPU-17 & Milky white, uniform & $178.9(0.167)$ & 40.1 \\
\hline
\end{tabular}

\subsection{GPC Analysis}

The prepared IWPUs were also characterized by GPC measurement and the results were summarized in Table 4. The number-average molecular weight $\left(M_{\mathrm{n}}\right)$ increased from $1.91 \times 10^{4} \mathrm{~g} \cdot \mathrm{mol}^{-1}$ to $3.91 \times 10^{4} \mathrm{~g} \cdot \mathrm{mol}^{-1}$ and the molecular weight distributions were narrow $\left(M_{\mathrm{w}} / M_{\mathrm{n}} \leq 1.3\right)$ except IWPU-13 $\left(M_{\mathrm{w}} / M_{\mathrm{n}}=1.45\right)$ as content of IL-Cl increased. The reason may be that this reaction was carried out by a two-step method: pre-polymerization and chain-extension. Due to the poor solubility of IL-Cl in acetone, the reacting process of IL-Cl and - $\mathrm{NCO}$ was rather smooth in the process of chain extension and the molecular weight distribution was narrow. When the content of IL-Cl was $16 \%$, $M_{\mathrm{n}}$ and weight-average molecular weight $\left(M_{\mathrm{w}}\right)$ reached the maximum value. While the content of IL-Cl continued to increase, the steric hindrance of imidazole heterocycle became larger and the reaction activity of reactants decreased, thus, the average molecular weight decreased.

Table 4. GPC results of IWPUs.

\begin{tabular}{|c|c|c|c|}
\hline Sample Name & $M_{\mathrm{n}} /\left(10^{4} \mathrm{~g} \cdot \mathrm{mol}^{-1}\right)$ & $M_{\mathrm{w}} /\left(10^{4} \mathrm{~g} \cdot \mathrm{mol}^{-1}\right)$ & $M_{\mathrm{w}} / M_{\mathrm{n}}$ \\
\hline IWPU-13 & 1.91 & 3.92 & 1.45 \\
\hline IWPU-14 & 3.25 & 4.16 & 1.28 \\
\hline IWPU-15 & 3.81 & 4.85 & 1.27 \\
\hline IWPU-16 & 3.91 & 4.89 & 1.25 \\
\hline IWPU-17 & 3.65 & 4.45 & 1.21 \\
\hline
\end{tabular}

\subsection{Thermal Analysis}

Thermal properties of IWPUs were studied using TGA and DSC analyses. Figure 2 showed TG and derivative thermogravimetric (DTG) curves of IWPU films with different IL-Cl content. The TG characteristics of films were given in Table 5. As shown in DTG curves, there were two weight loss stages: from $280{ }^{\circ} \mathrm{C}$ to $375^{\circ} \mathrm{C}$ and from $375{ }^{\circ} \mathrm{C}$ to $470{ }^{\circ} \mathrm{C}$, respectively. The first stage degradation was correlated with the decomposition of urethane due to the low breaking energy of $\mathrm{C}-\mathrm{N}$ bond [20]. At this stage, with the increase of IL-Cl content, the major decomposition temperature of IWPU films rose up from $309{ }^{\circ} \mathrm{C}$ to $329^{\circ} \mathrm{C}$ (increasing by about $20{ }^{\circ} \mathrm{C}$ ) due to more imidazole heterocycles [21]. The weight loss rate is $42.19 \%$, which is the same as the hard segment content of 
$40.29 \%$ of IWPU, indicating that the second stage of decomposition began after the hard segment was basically decomposed. The second stage (peak temperature at about $460{ }^{\circ} \mathrm{C}$ ) was attributed to the thermal decomposition of radical chain scission between -C-C- and -C-O- bonds of PTMG (soft segments), which further decomposed to produce carbon dioxide and hydrocarbons. Char yields at $500{ }^{\circ} \mathrm{C}$ increased with IL-Cl content increasing, showing the increasing flame retardancy because the carbon layer was an oxygen barrier and difficult to burn. Therefore, the flame retardancy of IWPU films was improved with adding IL-Cl. In conclusion, the addition of IL-Cl could improve the thermal stability of polyurethane films while the thermal decomposition of soft segment was seldom affected.

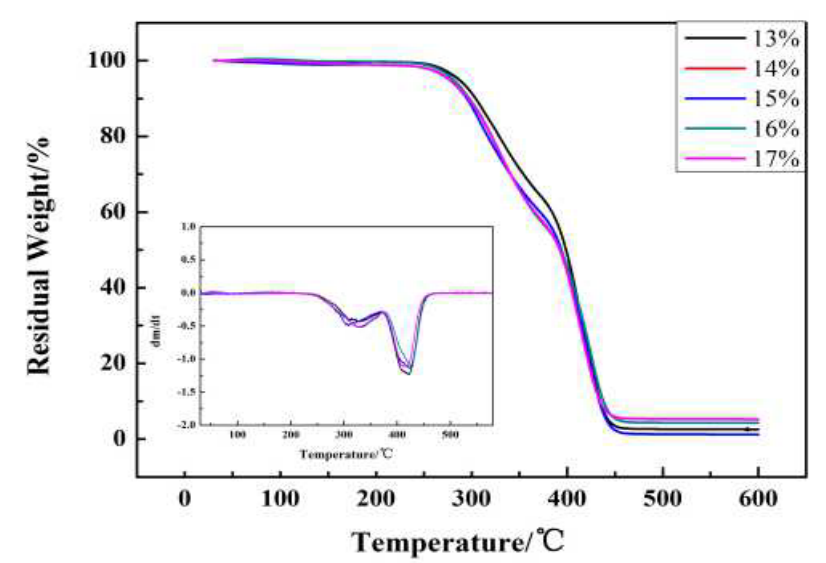

Figure 2. TGA curves of IWPU films (DTG curves are presented as insert).

Table 5. The TG characteristics of IWPU films.

\begin{tabular}{ccccc}
\hline Sample Name & $\boldsymbol{T}_{\mathrm{i}} /{ }^{\circ} \mathbf{C}$ & $\boldsymbol{T}_{\max \mathbf{1}} /{ }^{\circ} \mathbf{C}$ & $\boldsymbol{T}_{\max 2} /{ }^{\circ} \mathbf{C}$ & $\begin{array}{c}\text { Char Yields } \\
\text { at } \mathbf{5 0 0}\end{array}{ }^{\circ} \mathbf{C} \%$ \\
\hline IWPU-13 & 276.17 & 309.67 & 421.83 & 1.52 \\
IWPU-14 & 286.67 & 319.33 & 422.33 & 2.68 \\
IWPU-15 & 284.67 & 326.00 & 423.67 & 3.87 \\
IWPU-16 & 281.00 & 329.33 & 424.17 & 4.47 \\
IWPU-17 & 276.67 & 327.67 & 419.67 & 5.15 \\
\hline
\end{tabular}

( $T_{\mathrm{i}}$ was the initial decomposition temperature, $T_{\max 1}$ was the maximum decomposition temperature of hard segments, $T_{\max 2}$ was the maximum decomposition temperature of soft segments).

In addition, the DSC graphs corresponding to the IWPU films were shown in Figure 3 and the values of glass transition of soft segments and hard segments were summarized in Table 6 . IWPU showed two-phase structure since two thermal transitions have been detected. The first transition around $-78{ }^{\circ} \mathrm{C}$ was related to the glass transition of soft segment $\left(T_{\mathrm{gs}}\right)$ originated from PTMG structure. The second transition was associated to the hard segment consisting of urethane groups with glass transition $\left(T_{\text {gh }}\right)$ around $87^{\circ} \mathrm{C}$. Moreover, these two glass transitions were not greatly affected by the change of IL-Cl content. 


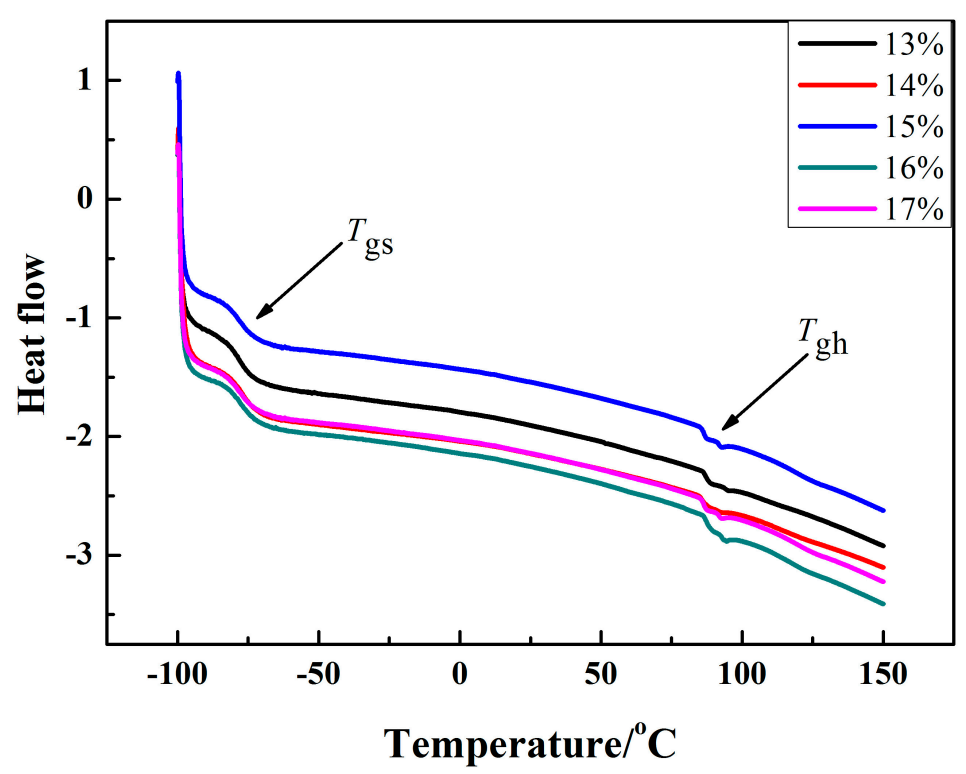

Figure 3. DSC curves of IWPU films.

Table 6. $T_{\mathrm{g}}$ of IWPU films.

\begin{tabular}{ccc}
\hline Sample Name & $\boldsymbol{T}_{\mathbf{g s}} /{ }^{\circ} \mathbf{C}$ & $\boldsymbol{T}_{\mathbf{g h}} /{ }^{\circ} \mathbf{C}$ \\
\hline IWPU-13 & -77.64 & 87.36 \\
IWPU-14 & -76.86 & 85.84 \\
IWPU-15 & -78.01 & 87.89 \\
IWPU-16 & -78.38 & 88.36 \\
IWPU-17 & -77.64 & 86.58 \\
\hline
\end{tabular}

\subsection{Mechanical Property}

Figure 4 illustrated the tensile strength and elongation at break curves of IWPU films with different IL-Cl content. As illustrated that as the content of IL-Cl increased, the elongation at break of IWPU films dropped from $1106 \%$ to $780 \%$. This can be ascribed that the higher the content of the hard segment, the more hydrogen bonds formed by $-\mathrm{N}-\mathrm{H}$ and $-\mathrm{C}=\mathrm{O}$ or $-\mathrm{N}-\mathrm{H}$. Meanwhile, the content of rigid urethane bonds and urea bonds rose up, which was not conducive to free movement and directional stretching of the molecular chain [22]. Nevertheless, when the content of IL-Cl increased, the tensile strength tended to enhance first and then decrease. The reason might be that the rigidity of the segments improved with the increase of imidazole ring contained by IL-Cl and hard phase micro-regions were easily formed between the segments [23]. Therefore, the tensile strength was optimized with a maximum value of $36 \mathrm{MPa}$. When the IL-Cl content further increased, the steric hindrance of the imidazole ring was obvious and the movement of the segment was hindered. Therefore, the tensile strength reduced [24].

\subsection{LOI Tests}

The flame retardancy of IWPU films were tested by LOI and the results were shown in Figure 5. The oxygen index value of IWPU films tended to rise up first with the increase of IL-Cl content in the range $13-16 \%$ and then decrease when IL-Cl content was 17\%. This phenomenon might be ascribed to the fact that the polyurethane matrices mainly contains both $\mathrm{N}$ and $\mathrm{Cl}$ elements [25]. The oxygen index value increased from $21.3 \%$ to $25.2 \%$ because of $\mathrm{N}-\mathrm{Cl}$ synergistic flame retardant effect. What's more, pure PU is highly combustible and its LOI value is only $16.7 \%$ according to the literature [26-28]. It can be concluded that the flame retardancy of IWPU was improved greatly compared with pure PU. 
IWPU reached the maximum value of LOI when IL-Cl content was $16 \%$, which was consistent with the results of TG.

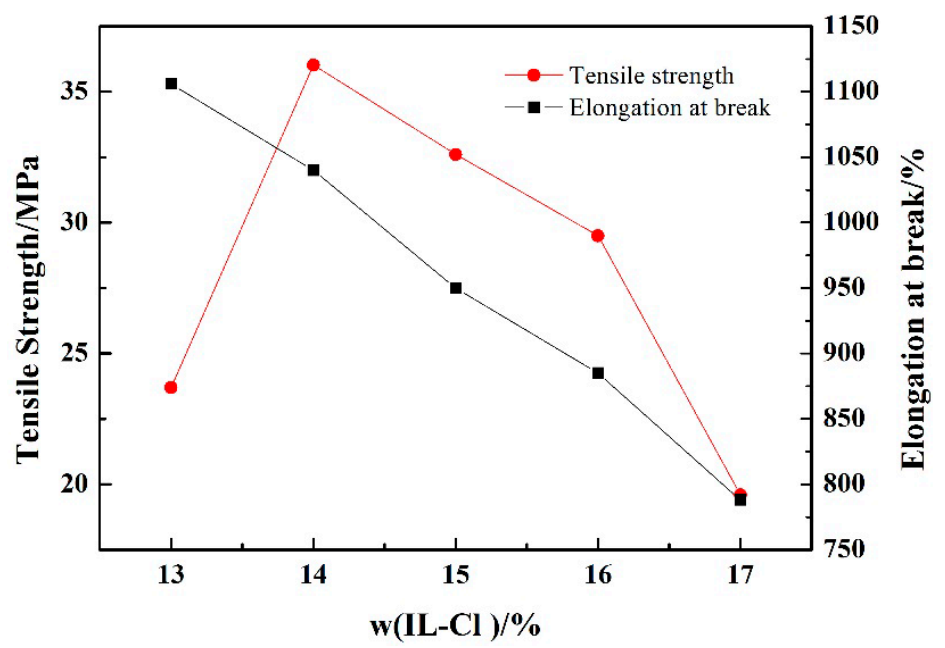

Figure 4. Mechanical property of IWPU films.

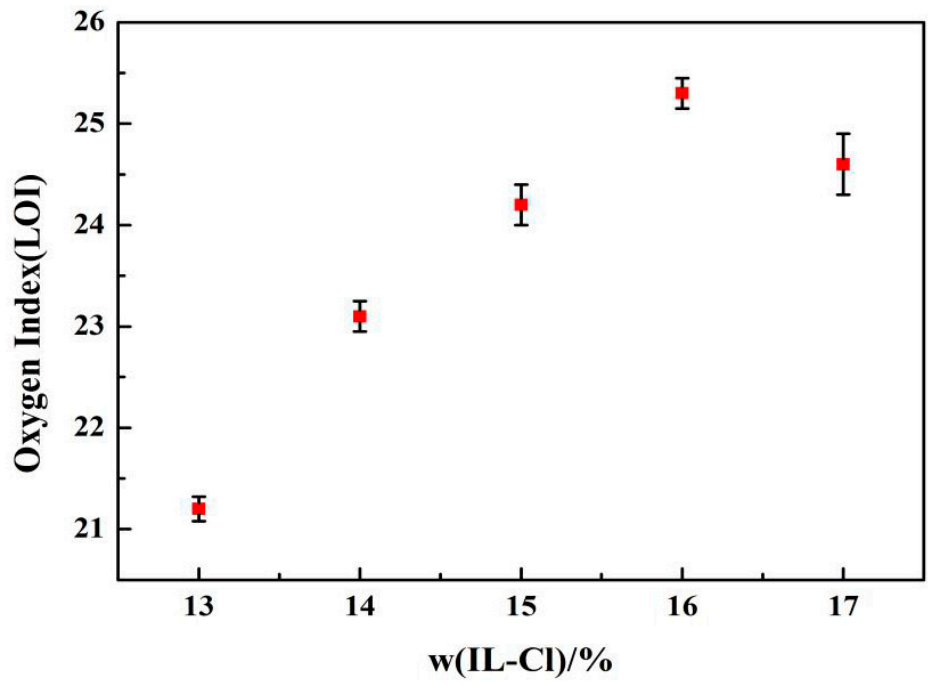

Figure 5. LOI results of IWPU films.

\subsection{Ionic Conductivity Tests}

To understand the ionic conductivity of IWPU films, EIS tests were carried out and the results were presented in Figure 6 and Table 7. The inset in Figure 6 showed the Nyquist plots of impedance for IWPU-13. The intercept on the $Z^{\prime}$-axis at high frequency end was corresponded to the bulk resistance $(\mathrm{Rb})$, which represents the resistance of electrolyte. The quasi-semicircle was corresponds to the charge transfer resistance (Rct) [29]. It can be seen that with the increase of IL-Cl content, the ionic conductivity $(\sigma)$ of IWPU films rose up, reaching a maximum of $1.2 \times 10^{-5} \mathrm{~S} \cdot \mathrm{cm}^{-1}$ and then decreased. This was mainly due to the increase of $\mathrm{Cl}^{-}$number as IL-Cl content increased. The big size of imidazolium cations caused the increase of $\mathrm{Cl}^{-}$number in the process of ion-dissociation [30]. Therefore, the interaction between the lone pair at the nitrogen atom in the polyurethane structure and the imidazolium cations enhanced, thus, ionic conductivity increased. Besides, the ionic conductivity decreased when IL-Cl content was 17\%. The reason might be that the systems became packed and the conduction process of $\mathrm{Cl}^{-}$was limited. In fact, the ionic conductivity of IWPU films was better than pure PU described in previous reports [31]. 


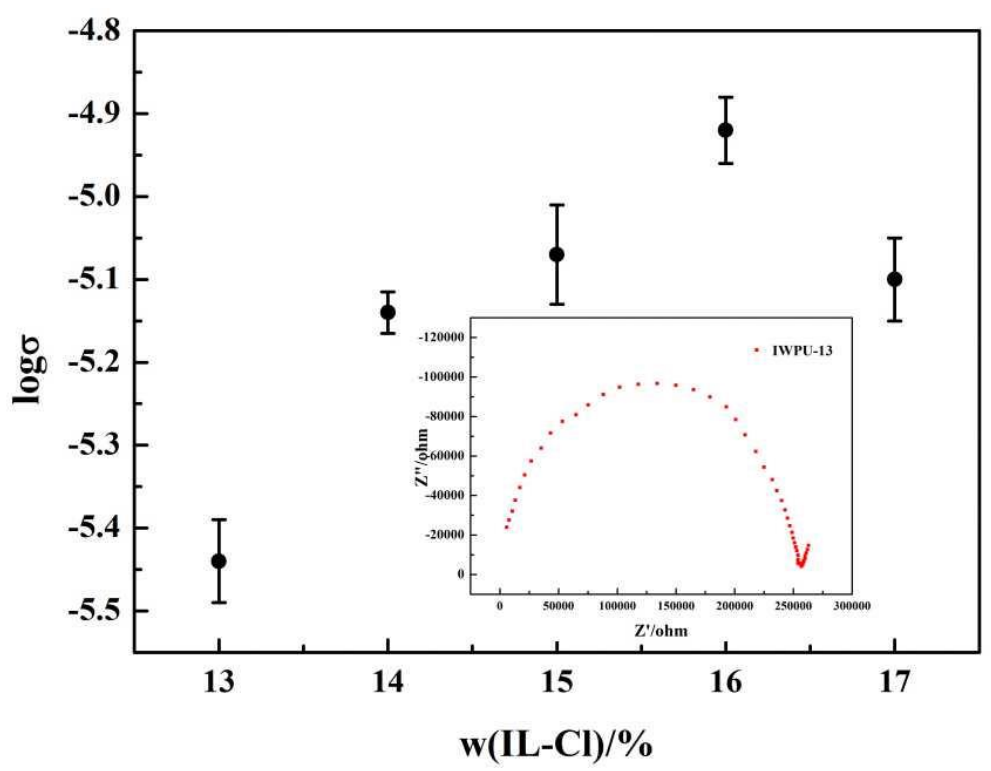

Figure 6. Ionic conductivity results of the IWPU films.

Table 7. Ionic conductivity values of IWPU films.

\begin{tabular}{cccccc}
\hline Sample Name & IWPU-13 & IWPU-14 & IWPU-15 & IWPU-16 & IWPU-17 \\
\hline$\sigma /\left(\mathrm{S} \cdot \mathrm{cm}^{-1}\right)$ & $3.6 \times 10^{-6}$ & $7.3 \times 10^{-6}$ & $8.4 \times 10^{-6}$ & $1.2 \times 10^{-5}$ & $7.9 \times 10^{-6}$ \\
\hline
\end{tabular}

\section{Conclusions}

In this paper, all-solid-state polymer electrolyte matrices (IWPUs) were fabricated using PTMG, IPDI, and IL-Cl. The particle size and zeta potential of IWPU were measured. The effect of ionic liquid on the motion of polyurethane chains and thermal property of IWPU films were characterized. Meanwhile, the results of mechanical property of IWPU films were improved a lot by adding IL-Cl, with tensile strength reaching $36 \mathrm{MPa}$ and elongation at break increasing to $1106 \%$, showing great flexibility. LOI analysis showed that the oxygen index value increased to $25.2 \%$ when the content of IL-Cl was $16 \%$. The highest ionic conductivity of $1.2 \times 10^{-5} \mathrm{~S} \cdot \mathrm{cm}^{-1}$ was obtained at room temperature with IWPU-16. The WPU films modified by ionic liquid can be promising candidate matrices for all-solid-state Li-ion battery.

Author Contributions: X.L.: Writing-Original draft, Validation, Formal analysis. Y.Z.: Validation. C.Z.: Investigation. Y.S.: Writing_Review \& Editing. Z.G.: Conceptualization, Writing-Review \& Editing. Y.L.: Conceptualization, Resources. All authors have read and agreed to the published version of the manuscript.

Funding: This recearch received no specific grant from any funding agency in the public, commercial or not-for-profit sectors.

Acknowledgments: We would like to acknowledge all the members of Key Laboratory for Ministry of Education of High Energy Density Materials at Beijing Institute of technology who continuously provide a collegial and supportive environment to help us conduct our work.

Conflicts of Interest: We declare that we have no financial and personal relationships with other people or organizations that can inappropriately influence our work, there is no professional or other personal interest of any nature or kind in any product, service and/or company that could be construed as influencing the position presented in, or the review of, the manuscript entitled. 


\section{References}

1. Yang, G.; Song, Y.; Wang, Q.; Zhang, L.; Deng, L. Review of ionic liquids containing, polymer/inorganic hybrid electrolytes for lithium metal batteries. Mater. Des. 2020, 190, 108563. [CrossRef]

2. Zhou, D.; Liu, R.; Zhang, J.; Qi, X.; He, Y.; Li, B.; Yang, Q.; He, Y.; Kang, F. In situ synthesis of hierarchical poly(ionic liquid)-based solid electrolytes for high-safety lithium-ion and sodium-ion batteries. Nano Energy 2017, 33, 45-54. [CrossRef]

3. Zhou, B.; Jo, Y.H.; Wang, R.; He, D.; Zhou, X.; Xie, X.; Xue, Z. Self-healing composite polymer electrolyte formed via supramolecular networks for high-performance lithium-ion batteries. J. Mater. Chem. A 2019, 7, 10354-10362. [CrossRef]

4. Ma, F.; Zhang, Z.; Yan, W.; Ma, X.; Sun, D.; Jin, Y. Solid Polymer Electrolyte Based on Polymerized Ionic Liquid for High Performance All-Solid-State Lithium-Ion Batteries. ACS Sustain. Chem. Eng. 2019, 7, 4675-4683. [CrossRef]

5. YKhoon, L.T.; Fui, M.W.; Hassan, N.H.; Su'ait, M.S.; Vedarajan, R.; Matsumi, N.; Kassim, B.M.; Shyuan, L.K.; Ahmad, A. Development of electrolytes towards achieving safe and high-performance energy-storage devices: A review. Chemelectrochem 2015, 2, 22-36.

6. Ma, Q.; Qi, X.; Tong, B.; Zheng, Y.; Feng, W.; Nie, J.; Hu, Y.S.; Li, H.; Huang, X.; Chen, L.; et al. Novel $\mathrm{Li}\left[\left(\mathrm{CF}_{3} \mathrm{SO}_{2}\right)\left(\mathrm{n}-\mathrm{C}_{4} \mathrm{~F}_{9} \mathrm{SO}_{2}\right) \mathrm{N}\right]$-based polymer electrolytes for solid-State lithium batteries with superior electrochemical performance. ACS Appl. Mater. Inter. 2016, 8, 29705-29712. [CrossRef]

7. Manthiram, A.; Yu, X.; Wang, S. Lithium battery chemistries enabled by solid-state electrolytes. Nat. Rev. Mater. 2017, 2, 16103. [CrossRef]

8. Cong, B.; Song, Y.; Ren, N. Polyethylene glycol-based waterborne polyurethane as solid polymer electrolyte for all-solid-state lithium ion batteries. Mater. Des. 2018, 142, 221-228. [CrossRef]

9. Deng, Y.; He, Z.; Cao, Q.; Jing, B.; Wang, X.; Peng, X. A novel high-performance electrospun thermoplastic polyurethane/poly(vinylidene fluoride)/polystyrene gel polymer electrolyte for lithium Batteries. Acta Chim. Slov. 2017, 64, 95-101. [CrossRef]

10. Bao, J.; Qu, X.; Qi, G.; Huang, Q.; Wu, S.; Tao, C.; Gao, M.; Chen, C. Solid electrolyte based on waterborne polyurethane and poly(ethylene oxide) blend polymer for all-solid-state lithium ion batteries. Solid State Ion. 2018, 320, 55-63. [CrossRef]

11. Bao, J.; Tao, C.; Yu, R.; Gao, M.; Huang, Y.; Chen, C. Solid polymer electrolyte based on waterborne polyurethane for all-solid-state lithium ion batterie. J. Appl. Polym. Sci. 2017, 134, 45554. [CrossRef]

12. Ren, N.; Song, Y.; Tao, C.; Cong, B.; Cheng, Q.; Huang, Y.; Xu, G.; Bao, J. Effect of the soft and hard segment composition on the properties of waterborne polyurethane-based solid polymer electrolyte for lithium ion batteries. J. Solid State Electrochem. 2018, 22, 1109-1121. [CrossRef]

13. Liu, L.; Wu, X.; Li, T. Novel polymer electrolytes based on cationic polyurethane with different alkyl chain length. J. Power Sources 2014, 249, 397-404. [CrossRef]

14. Kuo, P.L.; Tsao, C.H.; Hsu, C.H.; Chen, S.T.; Hsu, H.M. A new strategy for preparing oligomeric ionic liquid gel polymer electrolytes for high-performance and nonflammable lithium ion batteries. J. Membr. Sci. 2016, 499, 462-469. [CrossRef]

15. Liu, C.; Qiu, S.; Du, P.; Zhao, H.; Wang, L. An ionic liquid-graphene oxide hybrid nanomaterial: Synthesis and anticorrosive applications. Nanoscale 2018, 10, 8115-8124. [CrossRef]

16. Li, L.; Yang, X.; Li, J.; Xu, Y. A novel and shortcut method to prepare ionic liquid gel polymer electrolyte membranes for lithium-ion battery. Ionics 2017, 24, 1-7. [CrossRef]

17. Fasciani, C.; Panero, S.; Hassoun, J.; Scrosati, B. Novel configuration of poly(vinylidenedifluoride)-based gel polymer electrolyte for application in lithium-ion batteries. J. Power Sources 2015, 294, 180-186. [CrossRef]

18. Khanmirzaei, M.H.; Ramesh, S.; Ramesh, K. Polymer electrolyte based dye-sensitized solar cell with rice starch and 1-methyl-3-propylimidazolium iodide ionic liquid. Mater. Des. 2015, 85, 833-837. [CrossRef]

19. Zhu, Q.; Wang, Y.; Zhou, M.; Mao, C.; Shen, J. Preparation of anionic polyurethane nanoparticles and blood compatible behaviors. J. Nanosci. Nanotechnol. 2012, 12, 4051-4056. [CrossRef]

20. Behara, P.K.; Usha, K.M.; Guchhait, P.K.; Jehnichen, D.; Das, A.; Voit, B.; Singha, N. A novel ionomeric polyurethane elastomer based on ionic liquid as crosslinker. RSC Adv. 2016, 6, 99404-99413. [CrossRef]

21. Liu, G.; Kong, Z.; Wu, G.; Chen, J.; Huo, S. Preparation and properties of waterborne polyurethane/epoxy resin composite coating from anionic terpene-based polyol dispersion. Prog. Org. Coat. 2014, 77, 315-321. 
22. Mondal, T.; Basak, S.; Bhowmick, A.K. Ionic liquid modification of graphene oxide and its role towards controlling the porosity, and mechanical robustness of polyurethane foam. Polymer 2017, 127, 106-118. [CrossRef]

23. Yang, D.; Zhang, J.; Chao, Z. Synthesis and properties of waterborne polyurethane-based PTMG and PDMS as soft segment. Polym. Bull. 2016, 73, 293-308.

24. Kumagai, S.; Motokucho, S.; Yabuki, R.; Anzai, A.; Kameda, T.; Watanabe, A. Effects of hard- and soft-segment composition on pyrolysis characteristics of MDI, BD, and PTMG-based polyurethane elastomers. J. Anal. Appl. Pyrol. 2016, 126, 337-345. [CrossRef]

25. Luo, F.; Wu, K.; Li, Y.; Zheng, J.; Guo, H.; Lu, M. Reactive flame retardant with core-shell structure and its flame retardancy in rigid polyurethane foam. J. Appl. Polym. Sci. 2015, 132, 42800. [CrossRef]

26. Wei, H.; Zhu, Z.; Sun, H.; Mu, P.; Li, A. Graphene and poly(ionic liquid) modified polyurethane sponges with enhanced flame-retardant properties. J. Appl. Polym. Sci. 2017, 34, 45477. [CrossRef]

27. $\mathrm{Li}, \mathrm{Y}$. The study of melamine modified by imidazolium based ionic liquid [BMIM] $\mathrm{PF}_{6}$ on the flame retardancy of rigid polyurethane foam. Adv. Mater. Res. 2014, 1030, 241-245. [CrossRef]

28. Liu, Y.; Jiang, Z.; Miao, J.; Yu, Y.; Zhang, L. Properties of flame-retardant cellulose fibers with ionic liquid. Fiber. Polym. 2017, 18, 915-921. [CrossRef]

29. Zhang, D.; Zhang, L.; Yang, K.; Wang, H.; Yu, C.; Xu, D. Superior blends solid polymer electrolyte with integrated hierarchical architectures for all-solid-state lithium ion batteries. ACS Appl. Mater. Inter. 2017, 9, 36886-36896. [CrossRef]

30. Bao, J.; Shi, G.; Tao, C.; Wang, C.; Zhu, C.; Cheng, L. Polycarbonate-based polyurethane as a polymer electrolyte matrix for all-solid-state lithium batteries. J. Power Sources 2018, 389, 84-92. [CrossRef]

31. Kim, B.G.; Kim, J.S.; Min, J.; Lee, Y.H.; Choi, J.H.; Jang, M.C. A moisture-and oxygen-impermeable separator for aprotic Li-O-2 batteries. Adv. Funct. Mater. 2016, 26, 1747-1756. [CrossRef]

(C) 2020 by the authors. Licensee MDPI, Basel, Switzerland. This article is an open access article distributed under the terms and conditions of the Creative Commons Attribution (CC BY) license (http://creativecommons.org/licenses/by/4.0/). 